\title{
Pós-estruturalismo e teoria do discurso: perspectivas teóricas para pesquisas sobre políticas de currículo*
}

Marcia Betania de Oliveiral (D)

\section{RESUMO}

Este trabalho contesta a ideia de pesquisa como mero procedimento de verificação direta ou teste de uma hipótese ou teoria. Aborda o pós-estruturalismo como potencial produtivo na realização de pesquisas empíricas em ciências sociais e em educação, evidenciando contribuições das abordagens e dos referenciais analíticos pós-estruturalistas para tais pesquisas. Considera a teoria do discurso de Laclau e Mouffe na compreensão de políticas de currículo, entendendo que as escolhas metodológicas baseiam-se em propostas discursivas que devem ser reconhecidas e postas em jogo no processo de pesquisa. Além disso, destaca categorias teóricas, tais como discurso, sujeito, demandas e hegemonia, defendendo a ideia de currículo como prática discursiva, cultural, de poder e de significação. Por fim, compreende identificações políticas como cortes antagônicos e também como um fechamento provisório de significantes que se constituem como um texto, fruto de debates, da impossibilidade de pensamentos.

\section{PALAVRAS-CHAVE}

pós-estruturalismo; teoria do discurso; pesquisas em ciências sociais e em educação; políticas de currículo.

*Este texto, aqui revisado e ampliado, teve versão original apresentada na $37^{a}$ Reunião Nacional da Associação Nacional de Pós-Graduação e Pesquisa em Educação (ANPEd), em 2015, Grupo de Trabalho "Currículo". Disponível em: <http://www.anped.org.br/sites/default/files/trabalhogt12-4221.pdf>. Acesso em: 3 set. 2018.

'Universidade do Estado do Rio Grande do Norte, Mossoró, RN, Brasil. 


\title{
POST STRUCTURALISM AND THEORY OF \\ DISCOURSE: THEORETICAL PERSPECTIVES FOR RESEARCH ON CURRICULUM POLICIES
}

\begin{abstract}
This paper disputes the idea of research as a mere direct verification procedure or test of a hypothesis or theory. It addresses post-structuralism as productive potential in the conduct of empirical research in the social sciences and education, highlighting the contributions of post-structuralist approaches and analytical references.It considers Laclau and Mouffe's discourse theory in the understanding of curriculum policies, understanding that the methodological choices are based on discursive proposals that must be recognized and put into play in the research process. It emphasizes theoretical categories such as discourse, articulatory practices, subject, demands and hegemony. It defends the idea of curriculum as a discursive, cultural practice of power and meaning. It understands political identifications as antagonistic cuts, which approach different demands; a provisional closure of signifiers that constitute as a text, resulted of debates, of the impossibility of thoughts.
\end{abstract}

\section{KEYWORDS}

post-structuralism; discourse theory; research in social sciences and education; curriculum policies.

\section{POST-ESTRUCTURALISMO Y TEORIA DEL DISCURSO: PERSPECTIVAS TEÓRICAS PARA INVESTIGACIONES SOBRE POLÍTICAS DE CURRÍCULO}

\section{RESUMEN}

Este trabajo impugna la idea de búsqueda como mero procedimiento de verificación directa o prueba de una hipótesis o teoría. Aborda el post-estructuralismo como potencial productivo en la realización de investigaciones empíricas en ciencias sociales y en educación, destacando aportes de los abordajes y de los referenciales analíticos post-estructuralistas para tales investigaciones. Se considera la teoría del discurso de Laclau y Mouffe en la comprensión de políticas de currículo, comprendiendo que las elecciones metodológicas se basan en propuestas discursivas que deben ser reconocidas y puestas en juego en el proceso de investigación. Destaca categorías teóricas como discurso, sujeto, demandas y hegemonía. Defiende la idea de currículo como práctica discursiva, cultural, de poder y de significación. Comprende identificaciones políticas como cortes antagónicos, que aproximan diferentes demandas; un cierre provisional de significantes que se constituyen como un texto, fruto de debates, de la imposibilidad de pensamientos.

\section{PALABRAS CLAVE}

post-estructuralismo; teoría del discurso; investigaciones en ciencias sociales y educación; políticas de currículo. 


\section{INTRODUÇÃO}

A validade da perspectiva desconstrucionista na análise de políticas é considerada um dos desafios da pesquisa qualitativa, conforme Denzin e Lincoln (2006, p. 31). Esses autores afirmam que "os pesquisadores qualitativos defrontam-se com uma tripla crise [:] de representação, legitimação e práxis nas disciplinas humanas". De acordo com Aires (2015), tal crise faz parte dos cinco momentos históricos apontados por Denzin e Lincoln (1994) como coexistentes nas investigações qualitativas atuais.

O período da crise de representação, a primeira delas, em meados da década de 1980, vem trazer uma ruptura com "conceitos de objectividade, da cumplicidade com o colonialismo e da vida social estruturada a partir de costumes e rituais fixos próprios da antropologia clássica" (Aires, 2015, p. 11). Na expectativa de propor novos modelos de verdade e de método, essa crise representa a concepção de que o pesquisador qualitativo não pode mais captar diretamente a experiência vivida, que é criada no texto social por ele escrito. Essa crise defronta-se com o inescapável problema da representação, fazendo-o dentro de um esquema que questiona o elo direto entre a experiência e o texto.

A segunda crise, de legitimação, torna problemáticos os critérios tradicionais para avaliação e interpretação da pesquisa qualitativa, uma vez que envolve uma séria reconsideração de termos, tais como validade, capacidade de generalização e confiabilidade, estes já reteorizados em discursos diversos. Para os autores mencionados, as duas primeiras crises influenciam a terceira, que questiona se é possível realizar mudanças no mundo sendo a sociedade apenas um texto, evidenciando que elas se entrecruzam e se confundem, assim como as soluções para as questões que suscitam.

Nesse escopo, entendo, assim como defendido por Oliveira, Oliveira e Mesquita (2013), que pesquisa não deve ser vislumbrada como um procedimento de verificação direta ou teste de uma hipótese ou teoria. Assim, abordo o pós- estruturalismo como potencial para contribuir com abordagens e referenciais analíticos na realização de pesquisas empíricas em ciências sociais e em educação.

Discuto tais abordagens tomando como base o referencial teórico de Laclau (2011, 2013) e em estudos de Burity (2007, 2010), Costa e Lopes (2013), Lopes (2011, 2012, 2013, 2014a, 2014b), Lopes e Macedo (2011), Macedo (2006), Mainardes, Ferreira e Tello (2011), Oliveira, Oliveira e Mesquita (2013), Mendonça (2007, 2012), Rodrigues e Mendonça (2006).

\section{O PÓS-ESTRUTURALISMO E SUAS POSSÍVEIS CONTRIBUIÇÕES PARA A PESQUISA QUALITATIVA}

Desenvolvo o tema que dá título a esta seção apoiada em leitura de trabalhos de Alice Casimiro Lopes (2013), que, baseada na teoria do discurso, problematiza o impacto de teorias do currículo, ao abordar a relação entre teorias pós-críticas, política e currículo. $\mathrm{Na}$ referida leitura, é possível perceber diferenças entre os registros pós-estruturais, pós-coloniais, pós-modernos, pós-fundacionais e pós-marxistas, que são "usualmente englobados pelo mesmo rótulo de estudos pós-críticos em currículo" (Lopes, 2013, p. 7). 
A autora destaca que o pós-estruturalismo constitui-se em debate significativo, em que autores como Foucault e Lacan, inicialmente vinculados ao estruturalismo, vão construindo teorias que acabam questionando as concepções estruturadas de linguagem, especialmente "em torno da crítica a Saussure pela defesa da flutuação de sentidos do significante e pela desestruturação da unidade do signo"(Lopes, 2013, p.13). Lacan, ao inverter a relação saussuriana entre significante e significado, quebra a unidade do signo conferindo primazia ao significante, defendendo que o significante resiste à significação. Para ele, o sentido do que falamos é sempre posterior ao ato de fala, porque depende da relação com o outro, pré-existente a nós mesmos, entendido como linguagem.

Pode-se incluir nesse debate a concepção desconstrutivista de Derrida, que com sua noção de suplemento contribui definitivamente com a desconstrução da estrutura do signo, em uma expectativa de que "todo o conhecimento é então interpretado como um discurso e conectado ao poder" (Lopes, 2013, p. 12). Para Lopes (2013), no questionamento acerca de um centro fundante que garante a estruturalidade da estrutura, orientando-a, Derrida visa mostrá-la, destacando "o seu excesso, o que a perturba, a indecidibilidade associada ao que se pretende unívoco e identitariamente harmônico". Wolfreys (2009 apud Lopes, 2013, p. 14), afirma: "a estrutura exige uma relação com um exterior que a constitui”, uma presença, um fundamento que não pode ser explicado no interior da própria estrutura (Lopes, 2013, p. 14).

Como crítica ao sistema estático de regras na estrutura saussuriana da linguagem, Derrida (2001) afirma que não há sentidos originais na linguagem, mas sempre representações nas quais sentidos são suplementados. Se isso acontece, é porque estamos sempre tentando preencher uma lacuna na significação, tal qual na escrita, vista por ele como o suplemento do pensamento; aquilo que o representa (a escrita) em sua ausência (o pensamento) (Derrida, 2001).

Outra categoria colocada em crise no estruturalismo pela crítica ao existencialismo e ao humanismo é a de sujeito. Os pós-estruturalistas consideram a ação dos sujeitos um aspecto crucial para a compreensão das políticas e enfatizam a fluidez do poder e sua posse pelos diferentes agentes (Mainardes, Ferreira e Tello, 2011). O sujeito lacaniano questiona o sujeito cartesiano e sua estrutura enquanto tal; não o eliminando enquanto sujeito, mas destacando o seu descentramento, questionando "o seu caráter de origem ou fundamento, tal como também se opera ao questionar a estrutura" (Lopes, 2013, p. 13). O sujeito existe "como resultado de um ato de decisão, acrescenta Laclau, habitada pela indecidibilidade, suplementa Derrida" (Lopes, 2013, p. 13).

Para Lopes (2013, p. 13), o pós-estruturalismo "não se constitui como um movimento ou um conjunto de doutrinas comuns", visto que autores que optam por essa perspectiva de análise buscam "salientar a pluralidade dos jogos de linguagem que tornam provisório o processo de significação, sem fechamento final”.

De acordo com Lopes (2013), o pós-estruturalismo busca na abordagem foucaultiana a sua análise do poder, por meio do diagnóstico das estruturas de "saber - poder" e da denúncia das tecnologias da dominação. Para Foucault (2004), o poder não é apenas repressivo, mas também produtivo, visto que cria novos saberes, os quais podem tanto oprimir quanto libertar. O poder está disperso por todo o sistema social, descentrado, não localizado em um único local, como no Estado. Além disso, o poder 
está estreitamente vinculado ao saber, "fazendo parte da constelação de 'saber-poder', o que significa que o saber no sentido das práticas discursivas é produzido no exercício das práticas de poder, a serviço do controle do corpo"(Peters, 2000, p. 44). Tudo está imerso em relações de poder e saber, que se implicam mutuamente.

Discursos instituídos de política são entendidos como formas "de ordenar dimensões capazes de subverter e refundar o social de outras maneiras, reconhecidamente antagônicas e conflituosas" (Lopes, 2014b, p. 1). Assim também, ao questionarem os fundamentos ( $g$ round) de noções como verdade, projeto, classe social, realidade e sujeito, os "registros teóricos pós-críticos [...] abalam a própria compreensão do que vêm a ser o currículo e seu caráter político" (Lopes, 2013, p. 2). Vale então dizer que em uma perspectiva pós-estrutural toda significação remete ao contexto e à contingência, não a um geral, exceto como construção parcial.

Com base em estudos de Mainardes, Ferreira e Tello (2011, p. 163), destaco, portanto, algumas das contribuições das abordagens e dos referenciais analíticos para essas pesquisas pós-estruturalistas e pluralistas: rompem com modelos lineares, constituindo-se como um diferencial significativo quando comparados com pesquisas que dispensam o emprego de referenciais teóricos para fundamentar análises políticas quando investigadas; estimulam o pesquisador a analisar tanto o contexto amplo quanto os aspectos microcontextuais (escolas, salas de aula etc.). Ao mesmo tempo, tais referenciais e abordagens colocam aos pesquisadores uma série de desafios, entre eles está a sua necessidade de perceber as implicações da abordagem ou do referencial analítico que emprega, sempre vinculado a concepções epistemológicas específicas em seu trabalho acadêmico.

Pensar pós-estruturalmente na elaboração de pesquisas qualitativas revela, então, possibilidades e limites, como o de entender que "as possíveis estruturações passam a ser compreendidas como descentradas e desestruturadas", em que "a ideia de estrutura é substituída pela ideia de discurso” (Lopes, 2013, p. 13). Sem estruturas fixas que fechem de forma definitiva a significação, mas apenas estruturações e reestruturações discursivas, em processos contingenciais em que são questionadas noções como transcendência e universalidade.

Isso posto, considero necessário discutir sobre a articulação da teoria do discurso de Laclau e Mouffe (2011) na realização de pesquisas empíricas em ciências sociais e educação, particularmente sobre políticas de currículo. Entendo que as escolhas metodológicas nessas pesquisas baseiam-se em propostas discursivas que devem ser reconhecidas e postas em jogo no processo de pesquisa. Oliveira, Oliveira e Mesquita (2013, p. 1.334) destacam que, tendo em vista que "as formulações teóricas também são discursos opacos e interessados, que constituem a realidade e que, portanto, não podem representá-la de forma neutra ou imparcial", uma teoria passa a ter relevância em um dado contexto dependendo de sua capacidade de interação com ele, "de ser apropriada por/para ele e de produzir sentidos que possam mobilizar a realidade". Esses autores acreditam que uma pesquisa orientada pela teoria do discurso "é virtualmente incompatível com o modelo hipotético-dedutivo, [...] e demanda a articulação de um modelo de explicação que reconheça o caráter precário, contingente e intrinsecamente comprometido do próprio discurso científico"(Oliveira, Oliveira e Mesquita, 2013, p. 1.337). 


\section{PELA TEORIA: A POLÍTICA COMO DISPUTA DISCURSIVA}

Na perspectiva de Laclau e Mouffe (2011), a linguagem é apenas um dos componentes da estrutura discursiva. $\mathrm{O}$ discurso possui, enquanto sistema, a sua evidente dimensão linguística, mas não se restringe aos atos de fala ou ao que está estritamente escrito, englobando também ações e relações que possuem significado social, sendo resultado de uma prática articulatória que constitui e organiza essas relações.

Ao abordar o movimento da ideia do discurso como objeto para o discurso enquanto ontologia social, Burity (2010) apresenta uma lógica de compreensão de tal movimento. O autor esclarece que, no Brasil, a partir da década de 1970, com a circulação das primeiras publicações resultantes da recepção dos debates europeus (notadamente franceses) sobre a análise do discurso, cedo se percebeu que o discurso ia além de sua análise no âmbito do debate linguístico. O discurso apresentando-se, desde sempre, enquanto objeto de lutas pelo poder, pelo controle da enunciação, envolvendo a concepção e a implementação de táticas, estratégias, repertórios de ação, gestualidade, ritualização etc., que são parte integrante das formações discursivas como lugares de hegemonia. De acordo com Burity (2010, p. 11), nunca se está só com as palavras, falas, intenções manifestas ou veladas. Simplesmente "não há ação social sem significação, mas toda significação está inscrita — ainda que nunca plena ou definitivamente - num discurso".

Ainda de acordo com os registros desse autor, a teoria do discurso veio a ser assim chamada a partir do trabalho seminal de Laclau e Mouffe (1985), em que, apesar de ainda não nomear um campo novo, a centralidade da categoria discurso o invocava e ensaiava passos nessa direção. Burity (2010, p. 12) afirma que termos como pós-marxismo, teoria da hegemonia e teoria do discurso referem-se a "distintas dimensões dessa intervenção intelectual e política que suscitou intenso debate em várias partes do mundo, embora permaneça marginal nas ciências humanas e sociais brasileiras".

A teoria do discurso é definida como uma teoria política, devendo "ser lida como uma empreitada intelectual no sentido de fornecer ferramentas teóricas para a explicação de fenômenos sociopolíticos", em que discurso possui centralidade explicativa para esse projeto teórico (Mendonça, 2012, p. 205).

$\mathrm{Na}$ definição do próprio Laclau (2011, p. 9-10), discurso

[...] é uma totalidade relacional de significantes que limitam a significação das práticas e que, quando articulados hegemonicamente, constituem uma formação discursiva. E esta é conjunto de discursos articulados, por meio de diferentes práticas hegemônicas; entender uma formação discursiva significa entender um processo hegemônico: como são definidos os termos do debate político, quais agendas e ações são priorizadas, que instituições, diretrizes e normas são criadas.

A noção central do discurso "articula-se com um complexo arranjo de conceitos como prática articulatória, momentos, elementos, exterior constitutivo, antagonismo, hegemonia e significantes vazios", entre outros (Rodrigues e Mendonça, 2006, p. 9-10). Nessa perspectiva, a contingência e a precariedade são apresentadas 
como características peculiares das formações discursivas, e consequentemente das organizações político-sociais. A contingência refuta o potencial explicativo da realidade social enquanto determinismo econômico. A utilização desse conceito pela teoria do discurso infere também na negação de que a liderança da sociedade é um privilégio da classe operária em direção à sua própria emancipação. Assim, "as categorias marxistas são fortemente abaladas pela noção de contingência, tendo em vista que só as condições políticas e sociais reais e contingentes podem apontar qual é o grupo político capaz de ser o ponto nodal mobilizador" (Rodrigues e Mendonça, 2006, p. 10). Quanto à precariedade, a noção central do discurso "aponta para a inexorável finitude de toda e qualquer constituição hegemônica, uma vez que a hegemonia de determinado grupo político está sempre tendente a perder a sua força", tendo em vista que uma das características da política reside justamente em pensar que "toda vitória política é sempre uma vitória parcial e finita" (Rodrigues e Mendonça, 2006, p. 10).

Para Burity (2010, p. 16), as dimensões subjetiva e simbólica da prática política são constitutivas. Estaremos diante do político sempre que uma experiência antagonística ou um deslocamento na estrutura produzam articulações de tal forma que seu atendimento torna-se impossível nos limites da ordem estabelecida, e isso sem alterar essa última, sem por em xeque sua conformação hegemônica. As demandas são definidas por Laclau (2013) como resultado de uma articulação de necessidades que se encontra em situação peculiar com a ordem estabelecida, apresentando-lhe reivindicações. "Como essa ordem não pode absorver completamente a demanda, ela não pode se constituir como uma totalidade coerente" (Laclau, 2013, p. 26). Assim, é possível compreender que não há identidades políticas fixas, definidas a priori, anteriores ao processo de articulação e de tomada de decisão dos sujeitos. As identidades dos sujeitos que atuam nas políticas são constituídas pela forma como suas ações são incorporadas na prática articulatória, em um terreno precário e sempre vulnerável (Lopes, 2011, p. 42).

A articulação é definida por Burity (2010,p. 17) como termo-chave, que fala tanto "da construção de uma vontade coletiva pela transformação de uma demanda particular num objeto de investimento simbólico universal ou 'representativo' da comunidade em geral" quanto "das operações simbólicas que precisam ser realizadas para tal". A medida que demandas particulares se podem transformar em pontos nodais de articulação de vontades coletivas mais amplas, há um trabalho da articulação a ser realizado, que não é dado pela situação nem vem "de graça" pela boa vontade de outras necessidades (Burity, 2010, p. 17). Com a compreensão de que um discurso só se estabelece como totalidade estruturada em decorrência de uma prática articulatória, estabelecida como uma relação entre elementos, e que tal articulação empreendida modifica a identidade dessa relação, Lopes (2011, p. 36) esclarece que há sempre uma polissemia, uma multiplicidade de significados que pode subverter o processo de articulação.

Estudos como o de Costa e Lopes (2013) têm operado com a teoria do discurso por compreendê-la seja "como potente aporte teórico que viabiliza pensar a política como disputas discursivas em prol da hegemonização de significantes na política curricular, seja por intermédio de uma tendência ao seu esvaziamento" 
(Costa e Lopes, 2013, p. 63). Esses autores se afastam de concepções teóricas que analisam a política por meio de registros racionais e submetidos a outras esferas, como a econômica ou a jurídica - visto que a política, intrinsecamente conectada ao poder, para além de mostrar-se como disputa pela produção de um centro, o faz também "como disputa pela possibilidade de descentrar, de bloquear um poder que [a] pretenda cessar [...] pela produção de um centro definitivo"(Lopes, 2013, p. 63). Para os autores, essa teoria se insere, então, na perspectiva de pensar a subjetividade como em relação a um "para além", como adiamento, como se precipitando pela alteridade, que impossibilita o acabamento do "eu", das articulações, do fim da política, ao mesmo tempo em que "auxilia a não operar com a projeção de um horizonte, a ter em foco que o que se faz é um trabalho contínuo de articulação com vistas à hegemonização de um dado horizonte particular" (Costa e Lopes, 2013, p. 63).

\section{HEGEMONIA: ENTRE DESESTRUTURAÇÕES E DESCENTRAMENTOS}

Em sua obra Emancipação e diferença, Laclau (2011, p. 173) refere-se à adoção de um novo paradigma por Kuhn - embora Laclau o considere de transição afirmando que "não se pode dizer que a persuasão é redutível à força", não significa um abandono indiferente e indolor, mas envolve repressão de outras possibilidades: é o resultado de uma luta. Laclau ainda destaca haver um nome em sua tradição política, ao comentar sobre sua obra com Chantal Mouffe, Hegemony and strategy socialist, "que se refere à peculiar operação chamada persuasão, que só é constituída pela inclusão, dentro de si mesma, de sua violenta oposição: esse nome é hegemonia" (Laclau, 2011, p. 173).

Ao abordar sobre a relação entre necessidade e contingência, Laclau (2011) destaca que, assim como na relação entre o desejo que se quer suprimir e a decisão de suprimi-lo, não há conexão interna, em absoluto. Existe, porém, nessa relação, uma importante dialética a ser detectada, para além do conceito usual marxista, assim explicado:

Se cada um dos elementos que formam parte do bloco hegemônico tivesse identidade própria, sua relação com os outros seria meramente contingente; mas, se a identidade de todos os elementos contingentes depende de sua relação com os outros, tais relações, caso a identidade seja mantida, serão absolutamente necessárias. (Laclau, 2011, p. 174)

Costa e Lopes (2013) destacam que Laclau constrói a lógica desse processo, por analogia, com a lógica de condensação de desejo no objeto "a" lacaniano: "o objeto inexistente, não objetivo, que expressa o resto do que hipoteticamente se desejou e se perdeu; [o qual] só se sabe desejado pela perda, pela falta, pois escapa à simbolização" (Costa e Lopes, 2013, p. 61). Aquilo que é buscado, em todas as relações, e permanece no desejo sem nunca ser alcançado, sem que a falta por ele provocada nunca venha a ser preenchida e nem por isso a busca - que não cessa de resolver e reconstruir os sendimentos identitários pelo objeto do desejo - cesse. 
As ações que se desdobram em função dessa busca constituem o sujeito, tendo sua identidade sempre adiada (Costa e Lopes, 2013).

Para Laclau (2011, p. 175), em analogia ao jogo de xadrez, a lógica interna da operação hegemônica que subjaz ao processo de persuasão, "mesmo com um número indefinido de jogadores que possam vir a participar do jogo", tem suas regras sempre ameaçadas, visto que elas podem ser subvertidas, demonstrando o caráter inteiramente relacional da identidade, provisório, e que, mesmo homogeneizando as séries, mudará com a formulação de uma nova. De acordo com esse teórico do discurso, quando regras já existentes não conseguem homogeneizar "novos elementos (que) entram no quadro; [...] geralmente, a nova regra é aceita, não porque se goste dela, mas só porque é uma regra, porque ela introduz um princípio de coerência e inteligibilidade no caos" (Laclau, 2011, p. 175).

Hegemonia, nesse sentido, é para Laclau (2011,p. 173) “o terreno discursivo em que, na história do marxismo, o fundacionalismo começou a desintegrar-se”, passando a ser "o resultado de um processo contingente de articulação política num conjunto aberto, cujos elementos têm identidades puramente relacionais"(Laclau, 2011, p. 173). Nesse processo, "as identidades deixam de ser puramente imanentes a um sistema e exigem uma identificação com um ponto transcendente a esse sistema, [...] quando uma particularidade se torna o nome de uma universalidade ausente"(Laclau, 2011, p. 173).

Laclau (2011, p. 204) destaca que uma operação hegemônica "é essencialmente tropológica, mas exige movimentos estratégicos muito particulares a serem realizados dentro do continuum metafórico/metonímico". Assim, para esse teórico (2011, p. 213), "qualquer metonímia tem uma tendência natural de se transformar gradativamente em metáfora, tornando-se a relação de contiguidade, uma relação de analogia". Dada a imprevisibilidade de identidade dos agentes sociais, os momentos estratégicos de curto prazo, que só são possíveis em virtude das narrativas, operam pela analogia no ponto em que a metáfora e a metonímia se cruzam e limitam seus efeitos mútuos (Laclau, 2011, p. 216). Nisso consiste a hegemonia.

Nesse sentido, com base na teoria do discurso (Laclau e Mouffe, 2011), é possível pensar que o desafio na constituição de uma nova hegemonia é construir processos de articulação "em que a identidade hegemônica não seja constituída a priori, de fora do processo, e no qual uma dada particularidade possa assumir certo nível de universalidade provisório e reversível" (Lopes, 2006, p. 37).

\section{SUJEITOS E DEMANDAS NA CONSTITUIÇÃO DE PROCESSOS IDENTITÁRIOS}

Partindo do princípio pós-estrutural de que a estrutura social, assim como a linguística, é aberta e descentrada, Laclau e Mouffe (2011) recusam a determinação de identidades fixas, visto que tal fixação "cria a ilusão de que há algo positivo na definição dessas identidades, [...] de que elas remetem mesmo a um sentido que lhes é próprio" (Lopes e Macedo, 2011, p. 229). Ao fazê-lo, esses teóricos apontam não para a destruição das identidades, mas para o esvaziamento de um sentido necessário dado de antemão e estabelecido pela estrutura. 
Em um trabalho que discute a importância de se repensar a categoria do sujeito, "não para negá-la, mas para explorar os processos políticos que a informam", Burity $(1997$, p. 3) afirma que o pensamento de Laclau sobre essa questão se constrói "exatamente na referência cruzada à desconstrução derridiana e à lógica da identificação lacaniana, sujeito descentrado como sujeito da falta" (Burity, 1997, p. 18). O sujeito "emerge no momento da decisão, da resposta a um chamado que não escolheu [...] e perante o qual, ao responder (e só é sujeito em respondendo) torna-se responsável". Isso porque "precisamente [...] o sujeito calcula, decide; [...] o sujeito é infinitamente responsável face ao outro; [...] jamais consegue recolher-se no repouso do seu lugar próprio, onde ele é ele mesmo" e "nem por isso ele deixa de existir, morre, desvanece” (Burity, 1997, p. 18).

Dessa maneira, afirma Burity (1997, p. 21), “o sujeito da falta, a política e a hegemonia tornam-se momentos que se requisitam mutuamente". Por ser constitutivamente dividido/incompleto, o sujeito vai construindo-se por sucessivos atos de identificação. Por operar "num terreno histórica e contingentemente tecido, esse sujeito parcial pode refazer ou subverter a ordem vigente, apontando para outras possibilidades de organizá-la, particularmente nos momentos em que esta (a ordem) falha" (Burity, 1997, p. 21).

Lopes e Macedo (2011) registram que Laclau e Mouffe (1985) lançam mão da ideia de sujeito para melhor entender como o movimento de descentramento da estrutura é estancado, visto que não há regras que permitam fechar e centrar a estrutura. $\mathrm{Na}$ abordagem laclauniana, ao tomar uma decisão política, "é o sujeito [...] que fecha a estrutura no mesmo movimento em que se torna sujeito, em que se identifica com o outro", contrapondo-se à lógica de que "é a estrutura fixada que define a identidade dos sujeitos," ao tomar tal decisão (Lopes e Macedo, 2011, p. 227).

Sujeito é, por assim dizer, "o precipitado discursivo das articulações, uma decisão tomada em um terreno indecidível” (Lopes, 2014b, p. 10), em que "a plenitude de uma identidade é, assim, necessariamente impossível, pois não há um fundamento que garanta sua significação de uma vez por todas"(Lopes, 2014a, p.6). A "subjetivação é constituída como efeito de uma articulação"(Lopes, 2014b, p. 10), em processos de identificação/subjetivação, momentos de condensação provisórios e contingentes que não garantem a priori uma determinada mudança, visto ser esta efeito de uma ação política.

Assim, o sujeito se constitui por movimentos de reivindicações à ordem estabelecida (Laclau, 2013). Lopes e Macedo (2011, p. 229) destacam que o processo de identificação dos sujeitos se dá à medida que algumas manifestações ganham força e centralidade, possibilitando que haja a identificação de uns com os outros, em aglutinações que se desenvolvem com vista ao atendimento de suas exigências diferenciais.

A centralidade das demandas, em sua dinâmica não essencialista, se dá enquanto antagonismo, momento de fixação, provisório e contingente, e se faz em relação a uma diferença excluída da articulação discursiva, a qual "é simultaneamente condição de possibilidade da articulação (garante que a articulação exista) e de impossibilidade da articulação (confronta e bloqueia essa mesma articulação)" (Lopes, 2014b, p. 10). Assim, "as formas de garantir essa centralidade são definidas na luta política, pela articulação de grupos em torno de posições que precisam ser 
hegemonizadas, ou seja, 'vendidas' como de todo o grupo ou, mais eficazmente, de toda a sociedade" (Lopes e Macedo, 2011, p. 229).

Toda essa abordagem possibilita que se compreenda que é no processo de articulação, nas práticas articulatórias, que as identidades são constituídas e que os movimentos de reivindicações a elas associadas se deslocam, hibridizando-se, reconfigurando seus significados em virtude da articulação e do antagonismo. $\mathrm{O}$ sentido relacional da identidade se dá à medida que uma identidade ganha centralidade, visando, com isso, universalizar seus conteúdos particulares.

A complexidade do social, no entanto, impede necessariamente a completa universalização ou totalização desses conteúdos particulares, visto que, conforme destacado por Mendonça (2007, p. 250), "tentativas de fechamento completo de sentidos sociais são empreitadas sempre completas e precárias, [...] contingentes, uma vez que nada pode garantir que determinadas explicações ou efeitos de sentido, sejam capazes de serem universalizados necessariamente".

Destaco aqui a discussão de Mendonça (2007), na qual o autor afirma que, em uma pesquisa que tenha como base a teoria do discurso, não há como constituir sentidos sociais previamente ou se levar em conta identidades ou movimentos sociais totalmente constituídos, com projetos políticos existentes "desde sempre", em direção a um objetivo preciso. Dessa maneira, nunca um projeto político de determinado discurso tem seus sentidos plenamente constituídos (Mendonça, 2007, p. 250).

Laclau e Mouffe (2011) defendem a ideia de que há processos de identificação em que os sujeitos se aproximam e se constituem como grupos "identitários" politicamente ativos. O sujeito, entendido como subjetivação, "é um projeto inconcluso, um significante circulando a depender de uma significação sempre adiada. Seres linguageiros, cindidos e precários" (Lopes, 2013, p. 8), construções falidas.

A fluidez das identificações, conforme destacado por Lopes e Macedo (2011, p. 230), "vai no sentido das discussões pós-estruturais que destroem o binômio identidade/diferença e permitem pensar a diferença em si”. A tomada de decisão que constitui o sujeito é a criação da identificação fluida que por vezes nos parece uma identidade plenamente estabelecida. Assim, a identidade é apenas uma espécie de produto fictício da intervenção do sujeito, no sentido de conter a diferença. "Ela não preexiste à diferença, nem coexiste com ela", visto que "o descentramento da noção de identidade envolve mais do que a pluralização de identidades particulares"(Lopes e Macedo, 2011, p.230). Mesmo que haja hegemonias fortes e identificação estável, sempre haverá algum sentido que escape do controle, conforme já destacado ao longo deste texto.

Busco na leitura de Sérgio Costa (2006, p. 125) a compreensão de que "a concepção de diferença formulada, tanto por Bhabha como por Stuart Hall e Paul Gilroy, decorre do pós-estruturalismo e, mais particularmente, da noção de différance, conforme a acepção de Derrida”. Costa (2006) destaca que esse debate tem desdobramentos para campos tão diversos quanto a teoria feminista, o direito internacional e a teoria cultural. Para o autor, "ao cunhar o neologismo différance, como corruptela do vocábulo francês différence, Derrida indica a existência de uma diferença que não é traduzível no processo de significação dos signos, nem organizável nas polaridades identitárias". Tais distinções e classificações binárias "criam, ainda, a ilusão de representações completas, totalizantes, que não deixam resíduos” (Costa, 2006, p. 125). 
Nessa perspectiva, os movimentos identitários passam a ser vistos como importantes na denúncia do esgotamento das identidades únicas, seja do Estado, seja da classe, fortalecendo as identidades locais, sustentadas muitas vezes por discursos essencializadores. Tais movimentos (entre outros, como questões sociais, de gênero, de raça) podem ser destacados como contribuições ao debate ao debate (não apenas) curricular.

Essas identidades "podem ser outra face do mesmo discurso que localiza nos sujeitos algo comum capaz de identificá-los em um outro grupo" (Lopes e Macedo, 2011, p. 222), elas não pretendem aniquilar em demasia as manifestações identitárias e reivindicam direitos legítimos dos sujeitos, visto que frequentemente os movimentos identitários "não se contrapõem uns aos outros". Tal abordagem possibilita "pensar lutas políticas baseadas numa identificação provisória entre os sujeitos, cuja diferença central em relação à ideia de identidade é que ela não tem fundamento de nenhuma espécie" (Lopes e Macedo, 2011, p. 228).

As autoras (2011, p. 230) evidenciam ainda que, embora algumas políticas de currículo busquem regular os sujeitos, "desconsiderando a pluralidade de suas identidades, renunciando a outras possibilidades de ser", faz-se necessário destacar o reconhecimento do Outro (identificação) na constituição de projetos educacionais, sem, no entanto, sufocar sua singularidade. Isso equivaleria a objetivá-lo e eliminaria a própria possibilidade de educar.

A teoria curricular fica, assim, diante de uma questão complexa que é a de construir alternativas em que o princípio de identidade e do reconhecimento não retire dos sujeitos a sua capacidade de criação (Lopes e Macedo, 2011, p. 231), procurando avançar em direção às concepções de estrutura descentrada e de sujeito da falta e da identificação, concebendo os projetos curriculares como híbridos e identitariamente descentrados, enunciados sempre a partir de uma simultânea negociação com o Outro. (Lopes, 2014b, p. 4).

\section{A (RE)SIGNIFICAÇÃO DO CONCEITO DE CURRÍCULO}

Em meio às questões até aqui discutidas acerca do pós-estruturalismo e da teoria do discurso de Laclau e Mouffe (2011), penso ser importante o debate sobre a articulação dessa teoria na realização de pesquisas em educação, particularmente sobre políticas de currículo, entendendo o campo educacional como um campo político, como produtor de sentidos, destituído de verdades fundantes, que desestabiliza consensos, gera antagonismos, dissensos e exclusões em torno de sua abordagem (Lopes, 2013).

De acordo com Lopes e Macedo (2010), o pensamento curricular no Brasil é marcado, especialmente a partir dos anos de 1990, pelo hibridismo. Os discursos que têm penetrado na abordagem do currículo vêm contribuindo com a constituição de novas identidades, tornando mais difusa a constituição de uma teoria do currículo, havendo certo deslizar das temáticas de um campo a outro. As autoras (2010) reconhecem que a redefinição do campo do currículo envolve a construção de novas preocupações, evidenciando como principal tendência a valorização de 
certa discussão da cultura, uma vez que, sob referências teóricas diversas, debates sobre multiculturalismo ou estudos culturais vêm sendo intensificados.

Assim, discussões em torno do hibridismo cultural com respaldo em autores como Homi Bhabha (2010), Nestor Garcia Canclini (2011), Stuart Hall (2000, 2003), entre outros de perspectivas pós-coloniais, possibilitam assimilar o currículo como um campo em que diferentes discursos são reterritorializados: um campo contestado em que se misturam influências, interdependências, rejeições (Lopes e Macedo, 2010, p. 47). Também como um campo impuro, cuja marca principal "é mescla entre o discurso pós-moderno e o foco político na teorização crítica" (Lopes e Macedo, 2010, p. 47).

Tomando a ideia pós-estrutural de que os currículos são cultura e, portanto, sistemas de significações e representações, eles trazem a marca colonial da regulação [...]. Pretendem direcionar os sujeitos, criar efeitos de poder, e o fazem. No entanto, como cultura, são também necessariamente híbridos, ambivalentes. Não são, portanto, capazes de regulação total e é por isso que outros sentidos sempre irrompem. (Lopes e Macedo, 2011, p. 214)

Esse novo quadro híbrido, de acordo com as autoras, tem alterado de tal forma o campo do currículo, ampliando suas referências, que por vezes chega a assimilá-lo a outras áreas, como os estudos culturais ou a própria filosofia, conforme afirmam os críticos do pós-estruturalismo. Os discursos pós-coloniais tidos como "uma ferramenta útil para a compreensão dos fluxos culturais contemporâneos, contrapondo-se à ideia de diálogo multi ou intercultural", releem "a diversidade de culturas sob a ótica do fluxo e do hibridismo" (Lopes e Macedo, 2011, p. 208).

Ao propor o exercício de pensar as relações entre cultura e currículo para além das distinções binárias entre produção e reprodução cultural, Macedo (2006) entende ser necessário criar formas, de acordo com estudos de Canclini, que nos permitam tratar o poder como uma possibilidade mais oblíqua, compreendendo o currículo como espaço-tempo de fronteira cultural e a cultura como lugar de enunciação. Embora o faça dialogando com autores pós-coloniais, Macedo (2006) considera o conceito de hegemonia de Laclau e Mouffe (2011), que incorpora a alteridade e a iteração, uma alternativa teórica e política para lidar com contingências históricas em espaços híbridos de negociação.

Na leitura de Lopes e Macedo (2011, p. 202), assumir a perspectiva pós-estrutural em uma leitura do currículo implica "aceitar que todo e qualquer sentido somente pode ser criado dentro de sistemas de linguagem ou de significação". Para essas autoras, o sentido depende da inserção na materialidade de um sistema de classificação e em jogos de linguagem, frisando que, ao nomear, a linguagem institui a diferença tornando-se cúmplice das relações de poder, em um processo em que "aquilo que se sabe é movido por uma vontade de poder, assim como o poder exige que se saiba sobre aqueles que serão, por ele, governados" (Lopes e Macedo, 2011, p. 202).

Compreendendo a atividade de conferir significado como um processo cultural e discursivo, visto que práticas culturais são linguagens, o currículo "é, 
como muitas outras, uma prática de atribuir significados, um discurso que constrói sentidos; [...] uma prática cultural" (Lopes e Macedo, 2011, p. 202). Concordo com as autoras quando afirmam que redefinir a questão cultural no currículo em termos pós-estruturais (e pós-coloniais) "é tarefa fundamental para se pensar uma ação educacional contra a discriminação" (Lopes e Macedo, 2011, p. 202), cuja ação envolve "uma recusa que se fundamenta na denúncia de que não há tais culturas como coisas, a não ser como estratégia de dominação, como narrativas que buscam evitar que se pense diferente" (Lopes e Macedo, 2011, p. 215).

Há também uma recusa às leituras de pretensão realista "que operam com a identidade como fixa ou essencial [...] pressupondo que há algo real e específico desses sujeitos expressos pela nomeação" em "uma estrita representação entre o nome e a coisa", permitindo "falar pelo outro" (Lopes e Macedo, 2011, p. 223). Ainda para as citadas autoras, nas abordagens discursivas esses termos nada significam em si, mas apenas pela diferença em relação a outros termos que lhes servem de contraponto. "Ou seja, as identidades são definidas pela sua diferença em relação a outras identidades e não por algo que lhes é próprio; [...] recebem marcadores simbólicos que fazem com que sejam vistas como se fossem essenciais" (Lopes e Macedo, 2011, p. 223). Assim como os significados, as identidades também são construídas, produzidas pelos sujeitos no interior da cultura, no interior de sistemas de representação, e por seu intermédio em processos muito imbricados (Lopes e Macedo, 2011, p. 224).

Em constante movimento, o descentramento da estrutura "[...] não é interrompido pela aplicação de qualquer regra possível de ser imaginada" (Lopes e Macedo, 2011, p. 227). Nessa perspectiva, a ideia de identidade fixa para um currículo aberto à diferença perde o seu fundamento, visto que esse movimento é sempre estancado, ainda que sentidos continuem a vazar, fazendo com que haja a construção de identidades temporárias e fluidas.

Como parte dessa discussão, destaco que, por meio de estudos como o de Lopes (2012), trabalhar com a hegemonia em uma perspectiva discursiva pode revelar várias possibilidades para leituras no campo da educação, entre elas investigar a desestabilização da noção "de currículo como um conhecimento selecionado a partir de uma cultura mais ampla para ser ensinado a todos, em nome de um projeto de transformação social e de formação de sujeitos" (Lopes, 2012, p. 4).

Tenho feito um exercício (Oliveira, 2017) na tentativa de assimilar essa desestabilização: ao abordar a relação universal-particular acerca do Movimento pela Base Nacional Comum Curricular (BNCC), ${ }^{1}$ aponto a teoria do discurso na

1 Movimento que se formou em abril de 2013, "a partir do seminário internacional Liderando Reformas Educacionais. Desde então, um grupo diverso - composto por pessoas com longo histórico de atuação em instituições relevantes no cenário educacional brasileiro - decidiu se mobilizar pela causa da construção da Base Nacional Comum e vem buscando colocar em prática ações que possam facilitar e acelerar esse processo". (Disponível em: <http://basenacionalcomum.org.br/5-principios/>. Acesso em: 26 maio 2015). Para melhor compreensão sobre necessidades e possibilidades de uma BNCC, sugiro ler Alves (2014). 
perspectiva de tentar entender os modos como são construídas as subjetivações/ identificações em torno de uma unidade em relação à defesa dessa base. Essa leitura permite considerar discursivamente que,

da forma como apresentada, essa unidade parece defender ser essa não apenas "uma base" para a qualidade da educação; mas " $A B A S E$ ", que por si só parece querer se configurar como a própria qualidade e que não vê espaços para a existência de "outras bases". Como que colocando em xeque todas as demais propostas até então apresentadas (ou as muitas que não tiveram espaço para tal) na perspectiva de (re)formulações curriculares (consideradas) como não sendo de qualidade: sistema educacional incoerente, de currículos desalinhados e sem clareza, de professores mal formados (seja no âmbito inicial ou continuado) ou que não sabem o que fazer na ausência de uma base, de pactos, parâmetros, diretrizes ou avaliações de larga escala; alunos que não têm, ou não conseguem concretizar projetos de vida na ausência de um conjunto de conhecimentos considerados essenciais/válidos à sua formação, etc. (Oliveira, 2017, p. 6)

Outra possibilidade de leitura das/para as políticas de currículo é a desconstrução da ideia de "projetos de formação de um sujeito emancipado e consciente, capaz de dirigir a transformação social" (Lopes, 2012, p. 4), além de poder questionar o centramento do sujeito, com identidades fixas, abatendo a ideia de "projetos curriculares que têm por propósito formar uma dada identidade no aluno ou operar com uma identidade docente pré-estabelecida" (Lopes, 2012, p. 4). Assim, Lopes (2013) afirma: "se deixamos de ter projetos de futuro fixos e certezas em relação ao futuro, os projetos de formação para uma dada sociedade são contestados", tendo em vista que "sociedade é ela mesma uma categoria impossível, pois não há fundamentos absolutos que a sustentem como uma identidade plena"(Lopes, 2013, p. 18).

\section{CONSIDERAÇÕES FINAIS}

Quanto às discussões aqui levantadas, entendo como importante considerar o pós-estruturalismo como perspectiva teórica que possibilita contrapor a ideia da pesquisa qualitativa como representação de identidades fixadas ou de dado contexto da realidade, que necessita ser validada em virtude de sua aplicabilidade na prática. Como se a experiência vivida pudesse ser captada, retratada, representada e, enquanto tal, possível de realizar mudanças no mundo indicando soluções para as questões que essas modificações suscitam.

É possível assinalar, ainda, o pós-estruturalismo e a teoria do discurso como concepções teóricas para pesquisas sobre políticas de currículo, em bases discursivas, em contraposição à ideia de currículo como expressão do instituído. Longe do pensamento de reconhecer o pós-estruturalismo como "a solução" para leituras de políticas de currículo, em que um quadro de bem equipados teóricos derruba "uma dada hegemonia" no que concerne a produções desse/nesse campo de pesquisa, mas sim afirmo tal perspectiva teórica, especialmente a teoria do discurso de Laclau e Mouffe (2011), como possibilidade interessante para essas leituras. Concordo com Lopes (2013,p. 12) 
que, "caso as mesmas tentativas de síntese fossem feitas a partir de outros campos de estudo [...], certamente outras questões e noções seriam privilegiadas”.

As questões destacadas pela leitura pós-estrutural viabilizam considerar a possibilidade, bem como a necessidade de um currículo instituinte, que aproxime currículo de cultura, definindo-o como enunciação (Lopes e Macedo, 2011): o currículo entendido como uma prática discursiva, cultural, de poder e de significação. Também possibilitam considerar recusa às leituras de pretensão realista que operam com a identidade como fixa ou essencial, que se permitem e pretendem falar pelo outro nas políticas curriculares. Apoiada nos referenciais aqui destacados, considero que os significados, assim como as identidades, são construídos, produzidos pelos sujeitos no interior da cultura, no interior de sistemas de representação e, por seu intermédio, em processos muito imbricados.

\section{REFERÊNCIAS}

Aires, L. Paradigma qualitativo e práticas e investigação educacional. Lisboa: Universidade Aberta, 2015.

Alves, N. Sobre a possibilidade e a necessidade curricular de uma base nacional comum. Revista E-curriculum, São Paulo: PUC, v.12,n.3, out./dez.2014. Disponível em: <file:///D:/ Arquivos/Downloads/21664-55642-1-PB\%20(1).pdf>. Acesso em: 3 mar. 2016.

Внавна, H. K. O local da cultura. Belo Horizonte: UFMG, 2010.

Burity, J. Psicanálise, identificação e a formação de atores coletivos. Recife: Instituto de Pesquisas Sociais; Fundação Joaquim Nabuco, 1997. Disponível em: <http://biblioteca. clacso.edu.ar/Brasil/dipes-fundaj/20121203021343/joan2.pdf>. Acesso em: 20 nov. 2014.

. Teoria do discurso e análise do discurso: sobre política e método. In: WeBER, S.; Leithäuser, T. (Orgs.). Métodos qualitativos nas ciências sociais e na prática social. Recife: EdUFPE, 2007. p. 72-83.

.Teoria do discurso e educação: reconstruindo o vínculo entre cultura e política.

Revista Teias, Rio de Janeiro: UERJ, v. 11, n. 22, p. 7-29, maio/ago. 2010. 10.12957/teias

Canclini, N. G. Culturas hibridas: estratégias para entrar e sair da modernidade. 4. ed. São Paulo: UNESP, 2011.

Costa, H. H. C.; Lopes, A. C. Sobre a subjetividade/alteridade: conversas com Derrida e Laclau nas políticas de currículo. In: Tura, M. L. R.; Garcia, M. M. A. (Orgs.). Currículo, políticas e ação docente. Rio de Janeiro: EdUERJ, 2013. p. 51-71.

Costa, S. Desprovincializando a sociologia: a contribuição pós-colonial. Revista Brasileira de Ciências Sociais, São Paulo: ANPOCS, v. 21, n. 60, p. 117-183, 2006. Disponível em: <http://www.scielo.br/pdf/rbcsoc/v21n60/29764.pdf>. Acesso em: 18 set. 2017. http://dx.doi.org/10.1590/S0102-69092006000100007

Denzin, N.; Lincoln, Y. (Eds.). Handbook of qualitative research. Califónia: Sage, 1994. ; . A disciplina e a prática da pesquisa qualitativa. In:

(Orgs.). O planejamento da pesquisa qualitativa. Tradução de Sandra Regina Netz. Porto Alegre: Artmed, 2006. p. 15-42. 
Derrida, J. Posições. Belo Horizonte: Autêntica, 2001.

Foucault, M. A ordem do discurso. Tradução de Laura Fraga de Almeida Sampaio. São Paulo: Edições Loyola, 2004. (Aula inaugural no Collège de France, pronunciada em 2 de dezembro de 1970).

Hall, S. A identidade cultural na pós-modernidade. Rio de Janeiro: DP\&A, 2000.

. Da diáspora: identidades e mediações culturais. Belo Horizonte: Editora da UFMG, 2003.

Kunn, T. S. A estrutura das revoluções cientificas. 5. ed. São Paulo: Editora Perspectiva, 1997. Laclau, E. Emancipação e diferença. Rio de Janeiro: EdUERJ, 2011.

. A razão populista. Tradução de Carlos Eugênio Marcondes de Moura. São Paulo: Três Estrelas, 2013.

Laclau, E.; Mouffe, C. Hegemony and socialist strategy. Londres: [s.n.], 1985.

. . Hegemonía y estrategia socialista: hacia uma radicalización de la democracia. 3. ed. Buenos Aires: Fondo de Cultura Económica, 2011.

Lopes, A. C. Discursos na política de currículo. Currículo sem Fronteiras, v. 6, n. 2, p. 33-52, jul./dez. 2006.

Lopes, A. C. Políticas de currículo: questões teórico-metodológicas. In: Lopes, A. C.; Dias, R. E.; Abreu, R. G. Discursos nas políticas de currículo. Rio de Janeiro: Quartet, 2011. p. 19-45.

. A qualidade da escola pública: uma questão de currículo? In: TABOrDA, M. et al.(Orgs.). A qualidade da escola pública. 1. ed. Belo Horizonte: Mazza Edições, 2012. v. 1 , p. 15-29.

.Teorias pós-críticas, política e currículo. Educação, Sociedade E Culturas, Porto: CIIE, n. 39, p.7-23, 2013. Dossier temático: Configurações da Investigação Educacional no Brasil.Disponível em: <http://www.fpce.up.pt/ciie/sites/default/files/02.AliceLopes. pdf>. Acesso em: 20 nov. 2014.

. Ainda é possível um currículo político? In: Lopes, A. C.; Alba, A. (Orgs.). Diálogos curriculares entre Brasil e México. Rio de Janeiro: EdUERJ, 2014a.v. 1, p. 43-62.

. No habrá paz en la política. Debates y Combates, Buenos Aires: Fondo de Cultura Económica, v. 4, p. 1-25, 2014b.

Lopes, A. C.; Macedo, E. O pensamento curricular no Brasil. In: . Currículo: debates contemporâneos. 3. ed. São Paulo: Cortez, 2010. p. 13-54. .; ___ Teorias de currículo. São Paulo: Cortez, 2011.

Macedo, E. Currículo: cultura, política e poder. Currículo sem Fronteiras, Porto Alegre: [s.n.], v. 6, n. 2, p. 98-113, 2006.

Mainardes, J.; Ferreira, M. S. F.; Tello, C. Análise de políticas: fundamentos e principais debates teórico-metodológicos. In: BALl, S.J.; Mainardes,J.(Orgs.). Políticas educacionais: questões e dilemas. São Paulo, 2011. p. 143-172.

Mendonça, D. A teoria da hegemonia de Ernesto Laclau e a análise política brasileira. Ciências Sociais Unisinos, São Leopoldo:UNISINOS, v. 43, n. 3, p. 249-258, set./dez. 2007. 
. Antagonismo como identificação política. Revista Brasileira de Ciência Politica, Brasília, DF: UnB, n. 9, p. 205-228, set./dez. 2012.

Oliveira, M. B. “Mesmas oportunidades para todos": entre particularismo e universalismo, uma base nacional comum curricular. In: SEMINÁRIo InTERnacional Redes Educativas e Tecnologias, 2017, Rio de Janeiro. Anais eletrônicos... Rio de Janeiro:UERJ, 2017. Disponível em: <http://www.seminarioredes.com.br/ixredes/adm/ trabalhos/diagramados/TR76.pdf>. Acesso em: 23 ago. 2017.

Oliveira, G. G.; Oliveira, A. L.; Mesquita, R. G. A teoria do discurso de Laclau e Mouffe e a pesquisa em educação. Educação E Realidade, Porto Alegre: UFRGS, v. 38, n. 4,p.1.327-1.349, out./dez.2013. Disponível em: $<$ http://www.ufrgs.br/edu_realidade>. Acesso em: 20 nov. 2014. http://dx.doi.org/10.1590/S2175-62362013000400017

Peters, M. Pós-esruturalismo e filosofia da diferença. Uma introdução. Tradução de Tomaz Tadeu da Silva. Autêntica: Belo Horizonte, 2000.

Rodrigues, L. P.; Mendonça, D. (Orgs.). Ernesto Laclau e Niklas Luhmann: pós-fundacionismo, abordagem sistêmica e as organizações sociais. Porto Alegre: EDIPUCRS, 2006.

Wolfreys, J. Compreender Derrida. Petrópolis: Vozes, 2009.

\section{SOBRE A AUTORA}

Marcia Betania de Oliveira é doutora em educação pela Universidade Estadual do Rio de Janeiro (UERJ). Professora da Universidade do Estado do Rio Grande do Norte (UERN).

E-mail: marciabetaniauern@gmail.com

Recebido em 25 de junho de 2017 Aprovado em $1^{\circ}$ de dezembro de 2017 